\title{
O Estágio de Docência na formação dos pós-graduandos do Instituto de Botânica, SP, Brasil
}

\author{
Rodrigo S. Rodrigues ${ }^{1}$, Gustavo Henrique Jerônimo ${ }^{1}$, Pryscilla D. Almeida ${ }^{1,2}$, Viviana Motato-Vasquez ${ }^{1}$ e \\ (iTania Maria Cerati ${ }^{3,4}$
}

Recebido: 11.10.2017; aceito: 7.08.2018

\begin{abstract}
The Teaching Internship in the training of graduate students of the Instituto de Botânica, São Paulo State, Brazil). The Teaching Internship (TI) is understood as a curricular component that promotes the interrelation between theory and pedagogical practice, capable of bringing the graduate student closer to the educational activities. In this context, the objectives of this study were: 1) to evaluate students' perception about the contributions of the TI model of the Postgraduate Program in Plant Biodiversity and Environment of the Instituto de Botânica (PPGIBt) for teaching in higher education; 2) to investigate the perception of the PPGIBt professors about the importance of the curricular components related to the pedagogical practice in the training of graduate students. Electronic questionnaires were answered by 21 students (enrolled in the TI between 2010-2015) and 18 professors from the PPGIBt. Although the groups investigated cite that the PPGIBt prioritizes the research in relation to the training on pedagogical practice, they also recognize the importance of the pedagogical component for the professional performance in higher education. Even though requests and suggestions for improvement in the TI of the PPGIBt have been raised, in general terms, this model seems to be productive for a collective construction of the pedagogical practice in higher education and has elicited reflections on the future professional activity and social contribution of the research each student develops.
\end{abstract}

Keywords: faculty training, graduate program, higher education, scientists, teacher learning

RESUMO - (O Estágio de Docência na formação dos pós-graduandos do Instituto de Botânica, SP, Brasil). O Estágio de Docência (ED) é entendido como um componente curricular promotor da inter-relação entre teoria e prática pedagógica, capaz de aproximar o pós-graduando das atividades de ensino. Nesse contexto, os objetivos desse estudo foram: 1) avaliar a percepção dos discentes sobre as contribuições do ED desenvolvido pelo Programa de Pós-graduação em Biodiversidade Vegetal e Meio Ambiente do Instituto de Botânica (PPGIBt) para o exercício da docência no ensino superior; 2) investigar a percepção dos docentes do PPGIBt sobre a importância dos componentes relacionados à prática pedagógica na formação dos pós-graduandos. Questionários eletrônicos foram respondidos por 21 discentes (matriculados no ED entre 2010-2015) e 18 docentes do PPGIBt. Embora os grupos investigados citem que o PPGIBt valoriza a pesquisa em relação ao ensino da prática docente, existe o reconhecimento da importância do componente docência para a formação e atuação profissional no ensino de nível superior. Embora solicitações e sugestões de aprimoramento do ED no PPGIBt tenham sido levantadas, em termos gerais, esse modelo parece ser produtivo para a construção coletiva da prática docente no ensino superior e tem suscitado reflexões sobre a futura atuação profissional e a contribuição social da pesquisa que cada discente desenvolve. Palavras-chave: aprendizagem docente, cientistas, ensino superior, formação de professores, pós-graduação

\section{Introdução}

O crescimento do ensino superior no Brasil, principalmente nas décadas de 1950-1970, junto à sua valorização como agente promotor de empregabilidade e ascensão social, desencadeou novos processos nos âmbitos político e acadêmico com o propósito de facilitar o acesso dos egressos do ensino médio às universidades (Bertero 2007). A partir de 1970,

1. Instituto de Botânica, Programa de Pós-graduação em Biodiversidade Vegetal e Meio Ambiente, Avenida Miguel Stéfano, 3.687, 04301-902 São Paulo, SP, Brasil

2. Museu Paraense Emílio Goeldi, Programa de Capacitação Institucional, Av. Perimetral 1901, 66040-170 Belém, PA, Brasil

3. Instituto de Botânica, Núcleo de Pesquisa em Educação para Conservação, Centro Jardim Botânico e Reservas, Avenida Miguel Stéfano, 3687, 04301-902 São Paulo, SP, Brasil

4. Autor para correspondência: taniacerati@gmail.com 
o Programa Nacional de Pós-graduação (PNPG) vinculou os títulos de mestre e doutor ao exercício da docência no nível superior e à realização de atividades de pesquisa em universidades, dando início a uma pressão para formação quantitativa de profissionais capacitados. Esse quadro se acentuou na década de 1990, quando se verificou no cenário mundial um significativo aumento no número de acesso de estudantes aos cursos de graduação, especialmente em instituições de ensino privadas (Soares \& Cunha 2010), ampliando ainda mais a demanda sobre a formação de docentes habilitados. Entretanto, segundo Arroio et al. (2006), a exigência de titulação para a docência no nível superior não garantiu e não garante a qualidade dessa modalidade de ensino, visto que não houve nem há uma orientação pedagógica para a prática docente ao longo dos cursos de mestrado e doutorado.

A formação de docentes para a educação superior no Brasil é parte dos objetivos dos programas de pós-graduação, expressos no Parecer 977/65, do Conselho Federal de Educação, de 3 de dezembro de 1965, ainda em vigor (CFE 2005), cujo relator foi Newton Sucupira. Esse parecer torna os cursos de pósgraduação responsáveis pela formação dos docentes do ensino superior, sem, contudo, delinear a concepção de docência nem os saberes relacionados à prática pedagógica para esse nível (Lüdke 2005, Ribeiro \& Zanchet 2015). Além disso, o Parecer explicita três motivos fundamentais para a instauração do sistema de cursos de pós-graduação: a) formar professores competentes que possam atender à expansão quantitativa do ensino superior, garantindo, ao mesmo tempo, a elevação dos atuais níveis de qualidade; b) estimular o desenvolvimento da pesquisa científica por meio da preparação adequada de pesquisadores; c) assegurar o treinamento eficaz de técnicos e trabalhadores intelectuais do mais alto padrão para atender às necessidades do desenvolvimento nacional em todos os setores (CFE 2005).

Nesse contexto, para fomentar a qualificação do futuro docente, a Coordenação de Aperfeiçoamento de Pessoal de Nível Superior (CAPES) emitiu a Portaria 052 de 26 de setembro de 2002, artigo 17 do Regulamento do Programa de Demanda Social da CAPES [reiterada, posteriormente, pelas portarias $\mathrm{n}^{\mathrm{o}} 34$ de 2006 e n $^{\circ} 76$ de 14 de Abril de 2010], onde institui, obrigatoriamente a todos os bolsistas CAPES, a realização do Estágio de Docência (ED) como parte integrante da formação dos pós-graduandos sensu stricto (CAPES 2002, 2010). De acordo com a
Portaria de 2010, o ED ganha o status de disciplina ao ser inserido na grade disciplinar dos cursos de pós-graduação. Sua estrutura curricular e execução são desenvolvidas no âmbito institucional e pautadas na participação do pós-graduando em atividades de ensino sob a supervisão de um orientador, tendo como objetivo a preparação para a docência e a melhoria da qualidade do ensino na graduação. Dessa forma, compete à Comissão de Bolsas da CAPES registrar e avaliar o ED para fins de crédito do pós-graduando (CAPES 2010).

Embora a Portaria CAPES 052 regulamente o ED e este passe a fazer parte de forma sistematizada das diretrizes da CAPES, a normatização per se ainda é pouco efetiva na formação do pós-graduando para atuação no ensino superior. Esse posicionamento fundamenta-se no conjunto de críticas ao modelo "laxo" de condução do ED apresentadas por Ribeiro \& Zanchet (2015). Segundo os autores, a ausência de diretrizes sobre como o ED deve ocorrer, que conhecimentos desenvolver, quais relações primar e qual concepção de formação para docência no ensino superior o sustenta, somada ao caráter de obrigatoriedade aos bolsistas, muitas vezes atribui uma conotação essencialmente burocrática à experiência.

Pimenta \& Anastasiou (2002), revisando a legislação vigente, sustentam que a formação para docência compete à pós-graduação nos níveis de mestrado e doutorado. Por outro lado, os programas de pós-graduação focam na formação dos estudantes para atuarem na área de pesquisa, geralmente partindo da premissa que os saberes da investigação em seu campo específico de conhecimento são suficientes para a docência ou se transformam automaticamente em saberes para a docência (Cunha 2006, Soares \& Cunha 2010). Para Bertero (2007), a importância que a maioria dos programas de pós-graduação dá ao treinamento docente é incipiente ou, por vezes, inexistente, uma vez que os esforços se concentram na pesquisa, na produtividade, na participação em eventos acadêmico-científicos e na elaboração da dissertação/ tese, atividades que, atualmente, constituem o cerne da pós-graduação. Diante desse quadro, segundo Krasilchick (2009), a deficiência de conhecimentos pedagógicos junto aos discentes pós-graduandos torna-se mais evidente diante do aumento da procura por cursos de metodologias para o ensino superior. Para Chamlian (2003), faz-se necessário ainda, uma formação no campo pedagógico para aqueles que vislumbram a docência superior e que, acima de tudo, desperte a valorização da tarefa do ensino. 
Os mecanismos atuais de admissão de docentes, de forma geral, pouco ou não consideram saberes específicos para uma prática pedagógica eficiente, como aqueles relacionados aos processos de ensino e aprendizagem, a avaliação ou planejamento, porém supervalorizam a produção científica, mesmo se tratando da contratação de um docente e não de um pesquisador (Arroio et al. 2006, Soares \& Cunha 2010). O professor iniciante recorrentemente possui dificuldades com a prática de ensino devido ao não domínio do campo pedagógico (Ribeiro \& Zanchet 2015), restando-lhe construir sua identidade docente a partir da experiência autodidata, modelos docentes experimentados durante a sua formação, vivências familiares, interação com colegas e/ou feedback dos seus alunos (Soares \& Cunha 2010).

Considera-se que, como profissional que realiza um serviço à sociedade, o professor universitário precisa atuar como profissional reflexivo, crítico, competente no âmbito de sua disciplina, além de estar capacitado a exercer a docência e realizar atividades de investigação (Pimenta \& Anastasiou 2002, Pimenta et al. 2003). Portanto, o ED, quando bem direcionado, pode vir a contribuir para a capacitação profissional do futuro professor.

De fato, mesmo considerando as atuais limitações, é perceptível o posicionamento favorável dos pósgraduandos em relação ao ED como uma das poucas oportunidades disponíveis (senão a única) durante seu curso para o desenvolvimento da sua prática docente (Vieira 2013), o qual lhes impõe como desafios a aprendizagem dos graduandos, a sua própria aprendizagem em relação à docência e a aproximação da prática em sala de aula, todos associados ao desenvolvimento da sua pesquisa (Verhine \& Dantas 2007).

Assumindo que o ED corresponde ao componente curricular promotor da inter-relação entre teoria e prática pedagógica, capaz de aproximar o pósgraduando das atividades de ensino, área na qual muitos atuarão profissionalmente, questiona-se de que maneira o ED capacita os discentes para o exercício da docência no ensino superior.

Diante desse questionamento, o presente estudo teve como objetivos avaliar a percepção dos discentes sobre as contribuições do ED do Programa de Pós-graduação em Biodiversidade Vegetal e Meio Ambiente do Instituto de Botânica (PPGIBt) para o exercício da docência no ensino superior e investigar a percepção dos docentes do PPGIBt sobre a importância dos componentes relacionados à prática pedagógica na formação dos pós-graduandos.

\section{O Programa de Pós-graduação em Biodiversidade Vegetal e Meio Ambiente do Instituto de Botânica}

A fim de que a pós-graduação brasileira atendesse de maneira adequada às demandas de desenvolvimento do país, foram fundamentais a ampliação e o espalhamento do parque científico e acadêmico por todo o território nacional. Para tanto, não bastava apenas criar novos campi universitários, uma vez que a pós-graduação de qualidade requer tempo de maturação institucional, infraestrutura complexa (frequentemente de alto custo), considerável número de pesquisadores produtivos e de alto nível, além de um ambiente consolidado de pesquisa (Gazzola \& Fenati 2010). Diante dessa realidade, as atenções se voltaram aos Institutos de Pesquisa (IPs) que abarcavam toda a complexidade para o desenvolvimento da pesquisa científica, sendo muitos deles centros de excelência no âmbito nacional e internacional. Assim, os IPs preencheram os requisitos necessários para abrigar programas de pós-graduação e contribuir para o cumprimento das metas nacionais para promoção do avanço científico e tecnológico (Gazzola \& Fenati 2010).

Ressalta-se que, enquanto a universidade tem a função de formar profissionais qualificados em diferentes áreas para atender às demandas da sociedade, os IPs, sem a obrigação de ensinar, dispõem, ao menos teoricamente, de condições ideais para: a) utilizar o conhecimento existente e adaptá-lo a uma finalidade específica; b) gerar novos conhecimentos para atender demandas pré-definidas; c) atender demandas específicas de se adaptar à intermediação com o setor produtivo (CAPES, 2010).

O Instituto de Botânica (IBt), órgão da Secretaria do Meio Ambiente do Estado de São Paulo, é uma instituição de pesquisa científica na área da botânica e meio ambiente que administra o Jardim Botânico de São Paulo e outras três Unidades de Conservação (UCs) no Estado. Desde 2002, possui um Programa de Pós-graduação em Biodiversidade Vegetal e Meio Ambiente sensu stricto, reconhecido através da Portaria MEC no 3949, publicada no D.O.U. de 31/12/2002, com duas áreas de concentração: Plantas Avasculares e Fungos em Análises Ambientais (PAF), com linhas de pesquisa em "Ecologia e Biomonitoramento de Ambientes Terrestres e Aquáticos" e "Diversidade e Sistemática"; e Plantas 
Vasculares em Análises Ambientais (PVA), com linhas de pesquisa em "Ecologia e Biomonitoramento de Ambientes Terrestres e Aquáticos", "Fisiologia e Bioquímica" e "Florística e Sistemática".

O PPGIBt destina-se à capacitação, atualização e ao aprimoramento de profissionais de nível superior, em aspectos científicos e tecnológicos, das áreas de botânica e microbiologia e suas interações com o meio ambiente (São Paulo 2014).

Implantar o ED no Programa foi um grande desafio, uma vez que a instituição não oferece cursos de graduação. Em conformidade com a portaria 052 da CAPES, o PPGIBt deveria associar-se a uma instituição de ensino superior (IES) que ofertasse tal modalidade de ensino. Todavia, o PPGIBt propôs à CAPES seu próprio modelo de ED, com uma série de normas e procedimentos para a sua realização. Após avaliação do modelo, a Coordenadoria de Desenvolvimento Setorial (CDS) entendeu não haver fundamentação legal que impedisse a efetivação da proposta, visto que os objetivos centrais do ED (i.e., preparação do discente para a docência e a qualificação do ensino superior) estavam contemplados no modelo proposto. Superados os entraves legais, o ano de 2005 marcou o início do ED pelo PPGIBt, que atualmente contabiliza 77 concluintes. A disciplina possui carga horária total de 75 horas, com duração de um semestre e cinco créditos validados.

\section{O modelo do Estágio de Docência do Programa de Pós-graduação em Biodiversidade Vegetal e Meio Ambiente}

O modelo de ED proposto foi criado pela Coordenação da Pós-graduação em conjunto com os pesquisadores da área de educação do IBt e aprovado pela CAPES. É vinculado ao Programa Institucional de Capacitação de Monitores e Educadores, cujo público alvo é composto por estudantes de graduação em Ciências Biológicas, Ciências Ambientais e áreas afins. Esses estudantes recebem capacitação para atuarem como monitores de educação ambiental no Jardim Botânico de São Paulo e nas UCs administradas pelo IBt. Uma parte do programa de capacitação é composta pelo "Curso de Atualização em Biodiversidade e Meio Ambiente", ministrado pelos discentes do PPGIBt, bolsistas de doutorado da CAPES. A carga horária do estágio de docência é de 75 horas e as atividades são: preparo das aulas, realização do curso e elaboração de material didático.

Neste modelo, os pós-graduandos bolsistas são responsáveis por: a) organizar o conteúdo programático compatível com sua área de pesquisa; b) planejar, elaborar e ministrar aulas teóricas e práticas utilizando as instalações e as coleções do Instituto; c) organizar, realizar e acompanhar atividades de coleta de material botânico na área do Jardim Botânico; d) realizar visitas aos laboratórios e às coleções biológicas; e) elaborar material didático sobre o tema abordado.

As aulas são pré-aprovadas pela coordenadora de estágio, que avalia, juntamente com os discentes, o conteúdo a ser abordado e as estratégias de ensino utilizadas, considerando a temática da própria linha de pesquisa do pós-graduando.

Em um modelo de ensino acadêmico, onde a concepção da docência relega os conhecimentos pedagógicos a um segundo plano e desvaloriza esse campo na formação dos futuros docentes (Cunha 2006), o modelo de ED proposto possibilita ao pósgraduando autonomia para a prática pedagógica e vivência da realidade da sala de aula.

\section{Material e métodos}

O presente estudo, por ser exploratório, fez uso da metodologia qualitativa e contou com dois grupos pesquisados: discentes e docentes do Programa de Pós-graduação em Biodiversidade Vegetal e Meio Ambiente do Instituto de Botânica (PPGIBt). A coleta de dados foi realizada por meio da aplicação de questionários eletrônicos distintos para cada um dos grupos amostrais, disponibilizados na plataforma Google ${ }^{\circledR}$. Cada indivíduo respondeu anonimamente ao questionário composto por questões abertas e fechadas. Os questionários foram enviados a 37 discentes, egressos ou ingressos do programa, que cursaram o ED entre 2011-2015 e a 51 docentes credenciados no programa, a maioria pesquisadores do IBt ou também professores externos. Os modelos dos questionários aplicados estão apresentados nos Apêndices 1 e 2. Os dados foram coletados e inseridos em uma planilha comparativa para posterior análise. A partir das respostas dadas por ambos os grupos amostrais foram elaborados gráficos para melhor visualização. Os dados obtidos são apresentados e discutidos a seguir.

\section{Resultados e Discussão}

Do total de questionários enviados, 21 retornaram do grupo dos discentes $(56,7 \%$ do total) e 18 dos docentes $(35,3 \%)$. 
Os dados coletados possibilitaram traçar um perfil dos discentes respondentes, dos quais: a) $57 \%$ são mulheres e 43\% são homens; b) $71 \%$ são da área de PVA e $29 \%$ da área de PAF; c) $67 \%$ cursaram a graduação em IES privadas, a maioria oriunda da licenciatura, sendo que $28,6 \%$ contaram com auxílio de bolsa parcial. Esses dados corroboram aqueles apresentados por Soares \& Cunha (2010), mostrando que as IES privadas atendem a demanda do aumento significativo nas últimas duas décadas de estudantes que acessam os cursos de nível superior.

\section{Discentes do Programa de Pós-graduação do Instituto de Botânica}

Com relação à experiência docente em ensino fundamental/médio/técnico, $76,2 \%$ dos respondentes declararam ter alguma experiência anterior à realização do ED. Para 23,8\%, o ED representou o primeiro contato com a prática docente.

Em suma, o PPGIBt recebe grande quantidade de discentes provenientes de IES privadas, sendo a maioria oriunda dos cursos de licenciatura e com experiência docente em algum nível. Provavelmente, este grande aporte de discentes oriundos de IES privadas ao PPGIBt esteja relacionado ao fato de o IBt não possuir curso de graduação, ao passo que as IES públicas absorvem, majoritariamente, seus próprios alunos graduados em seus programas internos.

Quanto à inserção dos discentes no mercado de trabalho, identificamos que três são docentes em universidades públicas (dois em São Paulo e um no Espírito Santo), três em universidades particulares na cidade de São Paulo, quatro são pesquisadores científicos/colaboradores que atuam no Museu Paraense Emílio Goeldi, Instituto de Pesquisa Jardim Botânico do Rio de Janeiro e Instituto de Botânica e um atua em escola técnica (ETEC). Os demais discentes ainda apresentavam vínculo com o programa de doutorado do IBt ou não informaram qualquer vínculo institucional.

Quanto à percepção dos discentes em relação às contribuições do ED para o exercício da docência superior, $100 \%$ dos entrevistados concordam que o enfoque da PPGIBt está na pesquisa científica, dos quais $19 \%$ relacionaram este enfoque também com pesquisa/ensino.

Dos entrevistados, $66,7 \%$ declararam que o ED contribuiu positivamente para a prática docente, especialmente na "preparação de aula prática e teórica" (Discente 6), no "aprimoramento da didática no ensino" (Discente 8) e na "melhor compreensão da dinâmica de uma aula voltada à graduação" (Discente 11). Entretanto, 28,6\% consideraram que a contribuição do ED foi razoável ou pouca e 4,7\% consideraram muito pouca contribuição. Corroboram esses dados o fato de $76,2 \%$ considerarem importante a criação de novas disciplinas voltadas à docência, justificando que "o IBt não é uma universidade, por isso tem grande carência de disciplinas voltadas ao ensino e prática docente" (Discente 18), ou que "considero importante a prática do ensino, visto que no IBt não temos muitas oportunidades [de exercício da docência]" (Discente 11).

Para 90\% dos discentes respondentes, o ED não interfere na condução da pesquisa e nas demais atividades curriculares, sendo considerado um momento de: a) aprimoramento didático - “(...) contribuiu para minha formação, pois sei que no futuro dar aulas será uma parte importante de minha vida profissional e a disciplina foi uma ótima oportunidade de aprender e exercitar isso (...)” (Discente 11), “(...) foi um exercício de passar o conteúdo do doutorado de uma forma mais simples e menos específica, o que para mim foi um desafio (...)" (Discente 10), “(...) foi uma excelente oportunidade para preparar aula teórica e prática (...)” (Discente 6), “(...) foi uma boa disciplina na qual treinamos nossa didática para futura atuação no ensino de nível superior" (Discente 4); b) reflexão sobre a vida profissional, uma vez que a carreira docente é um campo de trabalho profícuo para os egressos - "Considerando a realidade do Brasil, em que os doutores são majoritariamente inseridos no mercado de trabalho como professores (e não como pesquisadores), acredito ser fundamental um maior número de disciplinas de prática de ensino (não teoria, ressalto!)" (Discente 1); c) reflexão sobre a contribuição social da ciência - "foi um momento de refletir sobre o que a minha pesquisa poderia contribuir na educação formal e informal" (Discente 2).

O posicionamento favorável dos discentes em relação ao ED reitera os resultados apresentados por Yamamoto (2006), Bertero (2007) e Vieira (2013) mostrando a existência de uma lacuna na formação dos pós-graduandos que, muitas vezes, é percebida ao prestarem um concurso para ingresso na carreira de docência universitária.

Identificamos, contudo, que o modelo em vigor de ED do PPGIBt foi considerado pelo Discente 5 como um momento em que "não atuamos preparando uma aula de verdade (planejamento de aula para o 
ensino superior), nem testamos nossas habilidades docentes e também não recebemos avaliação quanto ao desempenho didático(...)". Esses fatores devem ser reavaliados na condução das atividades, pois demonstram a necessidade de se trabalhar melhor a formação pedagógica aliada ao ED.

Na figura 1 é apresentada a opinião dos discentes sobre as habilidades desenvolvidas com a realização do ED. A organização didática (escolha de conteúdo e elaboração de aulas práticas e teóricas), a prática da oratória e tornar a linguagem científica compreensível foram as habilidades mais citadas.

Todavia, mesmo reconhecendo as potencialidades do ED para aquisição de habilidades para o exercício da docência, $71 \%$ dos discentes sugeriram mudanças na estruturação da disciplina, tais como: a) ampliação do período de estágio e atividades didáticas - "aumentar o tempo de duração para que possamos explorar mais o conteúdo dado nas aulas teóricas e práticas e também para que haja tempo hábil para a realização de uma avaliação dos alunos de graduação, para que nós (discentes da PG) possamos saber se passamos o conteúdo de forma eficaz e que os alunos tenham compreendido" (Discente 11); b) mais disciplinas relacionadas à prática de ensino ao longo do curso; c) possibilidade de estagiar também em universidades; d) avaliação mais aprofundada, tanto do desempenho ao longo do estágio quanto dos materiais didáticos produzidos; e) estender o ED a todos os discentes que cursam o doutorado e não apenas aos bolsistas da CAPES - "acredito que o ED do PPGIBt deveria ser obrigatório para todos os discentes. Durante o período de mestrado e doutorado, os discentes estão trabalhando apenas a habilidade de pesquisa, mas no

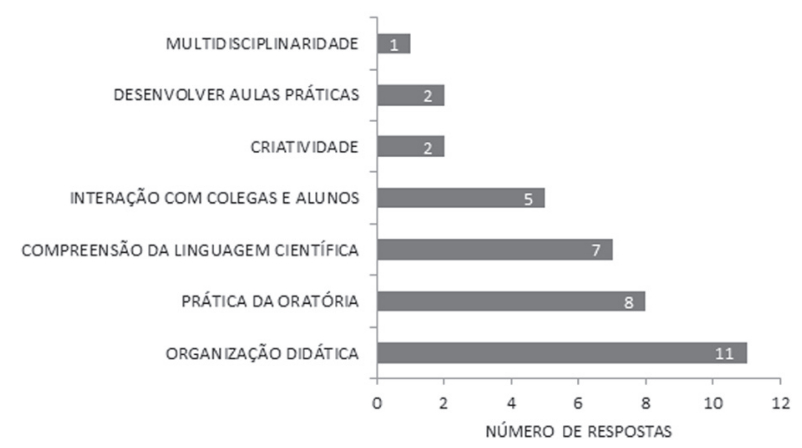

Figura 1. Habilidades para a prática docente desenvolvidas pelos pós-graduandos durante a realização do Estágio de Docência do PPGIBt.

Figure 1. Skills for teaching practice developed by the graduate students during the PPGIBt Teaching Internship. futuro podem precisar das habilidades em licenciatura, e seria esta disciplina uma ferramenta para isso" (Discente 9).

Diante de um dos pressupostos do ensino superior, onde o professor universitário precisa atuar como profissional reflexivo, crítico e competente no âmbito de sua disciplina, além de capacitado a exercer a docência e realizar atividades de investigação (Pimenta et al. 2003), os resultados apontam que o modelo de ED do PPGIBt viabiliza um momento acadêmico que suscita ao pós-graduando reflexões críticas, tanto no âmbito do exercício da docência quanto sobre a realidade profissional, favorecendo a formação do futuro profissional e suas relações com o trabalho.

De acordo com as respostas dos discentes, o ED é, de modo geral, percebido como a disciplina que vincula pesquisa e ensino, contribui para o aprimoramento da formação do pós-graduando para a docência no ensino superior e a sua realização não interfere no andamento da pesquisa. O ED e as atividades didáticas que ele promove estão consolidados, mas, sendo a docência superior um campo de trabalho almejado pela maioria dos doutores, percebe-se que ainda existe no Programa uma carência de disciplinas que contemplem este aspecto da formação dos pós-graduandos.

\section{Docentes do Programa de Pós-graduação do Instituto de Botânica}

Considerando os docentes do PPGIBt como constituintes fundamentais da estrutura do curso de pós-graduação, procurou-se investigar a sua percepção com relação aos componentes pedagógicos na formação dos pós-graduandos. Participaram da pesquisa 18 docentes, sendo 12 da área de PVA e seis da área PAF. Todos são pesquisadores científicos do IBt e, neste IP, a prática docente se dá, exclusivamente, através do curso de pós-graduação.

Ao serem questionados sobre estarem preparados para a docência superior no início da sua carreira, $22,2 \%$ dos docentes responderam negativamente, acreditando que a experiência é adquirida com o tempo de prática em sala de aula e considerando que "o curso de graduação, mesmo que de licenciatura, não propicia a prática da docência o suficiente" (Docente 18) e que, muitas vezes, o "percurso profissional é voltado para a pesquisa" (Docente 4 ).

Dentre os demais docentes (77,8\%) que declararam estarem preparados para a docência superior, parte afirma ter desenvolvido esta habilidade lecionando 
para o ensino médio, em cursos pré-vestibulares ou em cursos de língua estrangeira. Outros, porém, considerando estarem na carreira de pesquisadores científicos, declararam estar preparados apenas para ministrar aulas em nível de pós-graduação, pois foram "treinados e direcionados para estas atividades por seus orientadores (...), a lidar com diversas linguagens (...), de modo didático, para diferentes momentos e públicos" (Docente 12) e "apresentar palestras, auxiliar em aulas e co-orientar alunos de IC, o que [me] deu embasamento para iniciar a docência, mas somente em nível de pós-graduação" (Docente 4).

De forma geral, a experiência na docência é adquirida com a prática, podendo as disciplinas pedagógicas contribuir ou não com essa prática. Este "recorte" de experiências vai ao encontro das ideias apresentadas por Soares \& Cunha (2010), de uma composição de identidade docente gradual e, na maioria das vezes, autodidata.

Um ponto que subsidia a formação do futuro docente é o diálogo entre discente/orientador sobre questões relacionadas à carreira (Arroio et al. 2006). Verificou-se que $50 \%$ dos docentes afirmam discutir com seus orientandos tais questões. Neste contexto, dois tópicos são mais abordados: a didática, ou seja, como os conteúdos serão abordados e transmitidos “(...) para concorrer às vagas de professor universitário, é preciso saber apresentar uma excelente aula e também que as experiências anteriores podem enriquecer o currículo" (Docente 11), além disso, "para ter competitividade no mercado de trabalho acadêmico, é fundamental o discente saber transmitir conhecimentos e ter boa desenvoltura na sala de aula, tanto quanto nos laboratórios (...)" (Docente 15) e o conteúdo teórico, relacionado à "bagagem científica" e à titulação exigidas ao professor. Esta preocupação, embora legítima, parece decorrer do modelo de ensino que a maioria vivenciou enquanto aluno (Pimenta \& Anastasiou 2002) e da própria forma como atualmente são conduzidos os processos de seleção de professores para a composição dos quadros docentes em escolas e universidades, i.e., da adequação às demandas $\mathrm{e}$ critérios de seleção do mercado de trabalho.

A concepção de que a graduação enquanto pilar base da formação do pós-graduando tem por obrigação prover meios para a vivência da prática docente encontra sustentação no fato de a pós-graduação ser ainda considerada o universo da pesquisa em detrimento do ensino.

Os dados demostram que os docentes enfatizam a formação para a pesquisa como objetivo central do curso de doutorado. Para 61,1\% o Programa não oferece preparação adequada para os discentes atuarem na docência de nível superior, sendo que $83,3 \%$ deles assumem haver uma supervalorização da pesquisa em detrimento ao ensino. Essa supervalorização da pesquisa é justificada com base em argumentos que consideram que: a) o foco do doutorado não é docência - "O foco de formação de um doutor não é para a docência. Isso ele [o discente] deve receber no mestrado ou buscar em cursos na área de educação" (Docente 1); b) o IBt é prioritariamente um IP - "O IBt é prioritariamente um instituto de pesquisa e não uma instituição de ensino superior, portanto não possui histórico nem políticas voltadas à docência" (Docente 3), "O IBt é uma instituição quase que eminentemente de pesquisa, sendo normal haver uma tendência de se supervalorizar a mesma (...)" (Docente 15); c) a CAPES induz à essa situação - “(...) as normas da CAPES para pontuar os programas induz a essa situação, principalmente no que se refere à produção científica" (Docente 5), "Para existir, o PPGIBt depende 100\% da CAPES, que possui critérios de avaliação baseados essencialmente no desenvolvimento científico do pósgraduando" (Docente 10); d) a inexistência no PPGIBt de disciplinas para a formação docente - "Não há disciplina voltada para o preparo do discente para a docência ativa" (Docente 17), "(...) no meu entender a docência fica em segundo plano no nosso curso" (Docente 9).

Apesar de existir uma visão dissociada entre ensino e pesquisa nos programas de pós-graduação (Arroio et al. 2006, Verhine \& Dantas 2007), os dados obtidos sugerem uma tendência de mudanças nesse contexto, que podem estar associadas ao aumento significativo da demanda por professores qualificados para docência em IES.

Alguns docentes apontaram a realização de iniciativas isoladas que possibilitam o contato dos discentes com alguns aspectos da atividade de docência, tais como a apresentação de seminários, participação em congressos e solicitação de auxílio durante suas aulas (monitoria). A participação em atividades pedagógicas durante o doutorado recebe o apoio da maioria dos docentes (mesmo daqueles que informaram não solicitar o auxílio dos seus orientandos), que consideraram tais atividades como um aperfeiçoamento didático. Este aperfeiçoamento, além de promover a capacitação didática do discente, é ainda pensado em termos de contribuir para o preparo e apresentação das aulas de qualificação e defesa, aprofundamento da pesquisa e oportunidade de melhoria curricular (figura 2). 


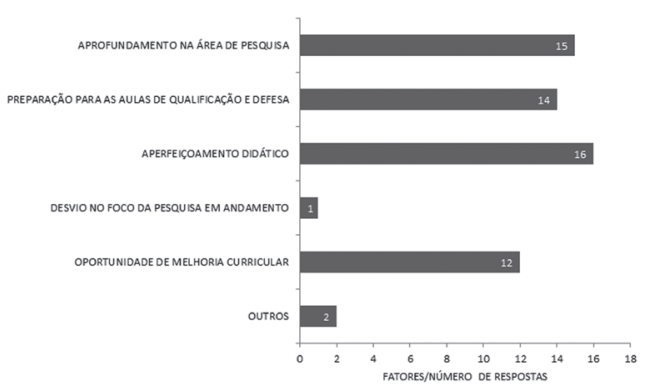

Figura 2. Opinião dos docentes sobre o que representa a participação dos discentes em atividades pedagógicas durante o doutorado.

Figure 2. Professors' opinion about the participation of the students in pedagogical activities during the Ph.D. course.

De acordo com os dados obtidos, as principais sugestões apontadas pelos docentes para o aperfeiçoamento da preparação dos discentes do PPGIBt para a docência foram: a) reformulação de disciplinas com algum componente pedagógico; b) engajamento dos discentes em atividades didáticas como cursos de extensão, realização de cursos de férias e palestras dentro e/ou fora da instituição; c) implementação de monitoria nas disciplinas do PPGIBt; d) realização de cursos extracurriculares com a colaboração de professores de outras instituições; e) implementação de avaliação didática da aula de qualificação.

\section{Considerações finais}

O desafio de implantar o ED em uma instituição que não possui cursos de graduação foi, até certo ponto, superado pelo PPGIBt. O modelo adotado se diferencia por possibilitar ao discente vivenciar a docência, uma vez que dá autonomia para seleção de conteúdo, estratégias de ensino e organização de atividades práticas e teóricas e, dessa forma, exercitar as diferentes vertentes que a prática docente exige. Essa autonomia gera um excelente engajamento nas atividades do ED, favorecendo a autoformação e estabelecendo uma dinâmica de interação e compartilhamento de saberes com seus pares e com os graduandos. Tal interação é produtiva para a construção coletiva da prática docente no ensino superior e para suscitar reflexões sobre a futura vida profissional e a contribuição social da pesquisa que cada discente desenvolve, especialmente para o ensino formal e não formal.

Consideramos que o modelo de ED tem investido em ações que contemplam a aprendizagem dos graduandos, a aprendizagem dos pós-graduandos em relação à docência e a aproximação prática com a sala de aula; ou seja, os três desafios da disciplina ED apontados por Verhine \& Dantas (2007).

A percepção dos pós-graduandos sobre o modelo de ED mostra que, embora os esforços (de discentes e docentes) estejam voltados à conclusão do doutorado, a publicação de artigos, entre outros, o ED não conflita com essas atividades e contribui positivamente para a prática docente. A preocupação com a formação para a docência no nível superior, além da formação científica, está fortemente arraigada entre os discentes pesquisados. Como consequência dessa experiência, os doutorandos mostram-se favoráveis à criação de novas disciplinas voltadas à prática pedagógica.

A trajetória de formação de ambos os grupos avaliados converge para o fato de que a experiência docente foi adquirida com a prática, num contexto de experimentação e aproveitada/aprimorada em situações posteriores. De modo geral, para discentes e docentes o curso de doutorado do PPGIBt é essencialmente voltado à pesquisa, sendo a docência um complemento trabalhado apenas em momentos específicos. Não obstante, ambos os grupos reconhecem a importância da docência na formação e atuação profissional no ensino superior.

Para concluir nossa reflexão sobre o modelo do ED do PPGIBt, apontamos a necessidade de contemplar as sugestões dos discentes, principalmente quanto à maior oferta de disciplinas direcionadas à prática pedagógica e a reformulação da avaliação do desempenho nas atividades do ED. As sugestões dos docentes também merecem ser analisadas, especialmente quanto à restruturação de disciplinas, o engajamento dos discentes em atividades didáticas, implementação de monitorias, cursos extracurriculares e avaliação didática da aula de qualificação.

O modelo de ED apresentado não é meramente uma disciplina obrigatória para obtenção de créditos e títulos, mas sim uma oportunidade de vivenciar a docência por meio de atividades integradas que contribuem para a formação da identidade profissional dos pós-graduandos. Sua articulação com disciplinas da área de educação cria espaço para discussões concernentes à metodologia de ensino, às dimensões do processo de aprendizagem e ao gerenciamento do trabalho pedagógico e, dessa forma, fortalece os vínculos entre ensino e pesquisa.

Acreditamos que o ED compõe o processo de formação pedagógica dos pós-graduandos, pois contribui para a construção do saber individual e 
coletivo, estimula o ato reflexivo, desenvolve a capacidade crítica e autonomia, ampliando os seus horizontes e capacitando-os para se tornarem agentes de transformação social.

\section{Agradecimentos}

Os autores agradecem a todos os discentes e docentes do PPGIBt que colaboraram com esta pesquisa por meio do preenchimento dos formulários eletrônicos; à Dra. Célia Leite Sant'Anna, coordenadora do PPGIBt, pelo apoio na realização desse estudo. GHJ e PDA agradecem a CAPES/ FAPESP e RSR e VMV agradecem a CAPES pelas respectivas bolsas de doutorado fornecidas.

\section{Literatura citada}

Arroio, A., Rodrigues Filho, U.P. \& da Silva, A.B.F. 2006. A formação do pós-graduando em química para a docência em nível superior. Química Nova 29: 1387-1392.

Bertero, C.O. 2007. A docência numa universidade em mudança. Cadernos EBAPE BR, 5: 1-11.

CAPES - Coordenação de Aperfeiçoamento de Pessoal de Nível Superior. 2002. Portaria n. ${ }^{\circ}$ 052, de 26 de setembro de 2002. Dispõe sobre a aprovação do regulamento para o Programa de Demanda Social. Diário Oficial da República Federativa do Brasil, Brasília, DF, 26 set. Disponível em http://www. capes.gov.br/export/sites/capes/download/legislação/ PortariaCAPES_052_2002 (acesso em 16-IX-2016).

CAPES - Coordenação de Aperfeiçoamento de Pessoal de Nível Superior. 2010. Portaria n ${ }^{\circ}$ 76, 14 de abril de 2010. Regulamento do Programa de Demanda SocialDS. CAPES, seção 1.

CFE - Conselho Federal de Educação. 2005. Parecer CFE n ${ }^{\circ}$ 977/1965, aprovado em 3 de dezembro de 1965. Revista Brasileira de Educação, 30: 162-173.

Chamlian, H.C. 2003. Docência na universidade: professores inovadores na USP. Cadernos de Pesquisa 118: 41-64.

Cunha, M.I. 2006. Diferentes olhares sobre as práticas pedagógicas no ensino superior: a docência e sua formação. Educação 27: 525-536.
Gazzola, A.L.A. \& Fenati, A. 2010. Pós-graduação brasileira no ano de 2020. In: Brasil, Ministério da Educação, Coordenadoria de Aperfeiçoamento de Pessoal de Nível Superior. Plano Nacional de PósGraduação (PNPG 2010-2020), 26. http://www.capes. gov.br/sobre-a-capes/plano-nacional-de-pos-graduacao/ pnpg-2011-2020 (acesso em 16-IX-2016).

Krasilchik, M. 2009. Docência no Ensino Superior. In: S.Z. Pinho (org.). Formação de Educadores: o papel do educador e sua formação. São Paulo: UNESP.

Lüdke, M. 2005. Influências cruzadas na constituição e na expansão do sistema de pós-graduação stricto sensu em educação no Brasil. Revista Brasileira de Educação 30: 117-123.

Pimenta, S.G. \& Anastasiou L.G.C. 2002. Docência no ensino superior. Cortez, São Paulo.

Pimenta, S.G., Anastasiou, L.G.C. \& Cavallet, V.J. 2003. Docência no ensino superior: construindo caminhos. In: R.L.L. Barbosa (org.). Formação de educadores: desafios e perspectivas. UNESP, São Paulo, pp. 267-278.

Ribeiro, G.M. \& Zanchet, B.M.B.A. 2015. Estágio de Docência: possibilidades e limites na formação de professores universitários. Currículo sem Fronteiras 15: 508-526.

São Paulo. Secretaria de Estado do Meio Ambiente. Instituto de Botânica. 2014. Portaria IBt no 17/2014, publicada em 07 de novembro de 2014, referente ao Regimento do Programa de Pós-graduação "stricto sensu" em Biodiversidade Vegetal e Meio Ambiente. Diário Oficial do Estado, Seção 1.

Soares, S.R. \& Cunha, M.I.D. 2010. Formação do professor: a docência universitária em busca de legitimidade. EDUFBA, Salvador.

Verhine, R.E. \& Dantas, L.M.V. 2007. Estágio de docência: conciliando o desenvolvimento da tese com a prática em sala de aula. Revista Brasileira de PósGraduação 4: 171-191.

Vieira, R.A. 2013. Formação pós-graduada e docência no ensino superior: mapeamento das discussões sobre o estágio de docência na RBPG/CAPES. Revista Contrapontos 13: 94-101.

Yamamoto, O.H. 2006. Graduação e pós-graduação em psicologia: relações possíveis. Revista Brasileira de Pós-Graduação 3: 270-281. 
Apêndice 1. Reprodução do questionário virtual aplicado aos discentes do curso de doutorado do PPGIBt.

Appendix 1. Reproduction of the virtual questionnaire applied to the Ph.D. students of the PPGIBt.

*Obrigatório

\section{Gênero*}

Marque apenas uma oval

-Masculino

-Feminino

2. Área de concentração*

Marque apenas uma oval

- Plantas Avasculares e Fungos em Análises Ambientais (PAF)

-Plantas Vasculares em Análises Ambientais (PAV)

3. A sua graduação foi realizada em*

Marque apenas uma oval

-Instituição pública

- Instituição particular em auxilio (bolsa)

- Instituição particular com auxílio (bolsa) parcial

-Instituição particular com auxílio (bolsa) integral

4. Durante sua graduação foram/foi cursada(s) disciplina(s) voltada(s) à prática docente (licenciatura)?*

Marque apenas uma oval

-Sim

•Não

5. Considerando sua resposta na questão anterior, avalie a contribuição destas disciplinas para realização das atividades didáticas ED-IBt.

Marque apenas uma oval

-Excelente contribuição

-Boa contribuição

- Razoável contribuição

-Pouca contribuição

-Muito pouca contribuição

6. Você já havia exercido alguma atividade docente (excetuando-se o estágio obrigatório requerido pelos cursos de licenciatura (quando aplicável) em período anterior a realização do ED-IBt? (marque todas as alternativas que julgar pertinente)*

Marque todas que se aplicam
-Sim, no nível fundamental

-Sim, no nível médio/técnico

- Sim, no nível superior

-Não

-Outro:

7. Em sua opinião, o enfoque do curso de doutorado do IBt está: (marque todas as alternativas que julgar pertinente)*

Marque todas que se aplicam

-Pesquisa

-Ensino

-Extensão

-Nenhuma

8. Em sua opinião, as atividades desenvolvidas no ED-IBt, contribuíram para a sua prática docente?*

Marque apenas uma oval

-Excelente contribuição

-Boa contribuição

-Razoável contribuição

- Pouca contribuição

-Muito pouca contribuição

9. Com base na sua experiência durante o doutorado, você considera importante a criação de mais disciplinas voltadas a pratica docente?*

Marque apenas uma oval

-Sim

•Não

10. Você percebeu a realização do ED-IBt como um desvio no desenvolvimento da sua pesquisa?*

Marque apenas uma oval

-Sim

•Não

11. Com base na resposta apresentada na questão anterior, discorra sobre razões do ED-IBt ter contribuído ou atrapalhado o desenvolvimento da sua pesquisa*

12. Cite ao menos 3 habilidades que você julga ter desenvolvido durante o ED-IBt*

13. Hoje, a sua atuação profissional está relacionada $\mathrm{a}^{*}$

-Ensino

- Pesquisa

-Ensino e pesquisa

- Nenhuma

- Outro: 
14. Se possível, identifique a instituição/empresa a qual você se encontra atualmente vinculado:

15. Quais seriam suas sugestões para o aperfeiçoamento do ED-IBt? *

Apêndice 2. Reprodução do questionário virtual aplicado aos docentes do PPGIBt.

Appendix 2. Reproduction of the virtual questionnaire applied to PPGIBt professors.

Obrigatório

1. Área de concentração*

Marque apenas uma oval

- Plantas Avasculares e Fungos em Análises Ambientais (PAF)

-Plantas Vasculares em Análises Ambientais (PAV)

2. Você se sentia preparado para exercer atividades de docência no início da sua carreira?*

Marque apenas uma oval

-Sim

•Não

3. Comente sua resposta anterior*

4. Na sua opinião, qual(is) o(s) objetivo(s) do curso de doutorado na formação do aluno*

5. Você discute com seu(s) aluno(s) de doutorado questões relacionadas a atividade docente?*

Marque apenas uma oval

-Sim

•Não

6. Caso tenha respondido afirmativamente na questão anterior, cite os principais tópicos abordados nestas discussões.
7. Você acredita que o curso de doutorado da PPGIBt prepara os alunos para a docência?*

Marque apenas uma oval

- Sim

•Não

8. Você acredita que no curso de doutorado da PPGIBt, a pesquisa é supervalorizada em relação ao ensino?*

Marque apenas uma oval

- Sim

•Não

Ambas possuem valorização equivalente

9. Comente sua resposta anterior.

10. Você costuma solicitar a ajuda de seus doutorandos em suas disciplinas?*

Marque apenas uma oval

- Sim

•Não

11. Na sua opinião a participação dos doutorandos em atividades docentes durante o curso representa: (marque todas as alternativas que julgar pertinente)*

Marque todas que se aplicam

- Aprofundamento na sua área de pesquisa

- Melhor preparação para as aulas de qualificação e defesa

-O aperfeiçoamento didático do aluno

-Um desvio no foco da pesquisa em andamento

- Oportunidade de melhoria curricular

-Outro:

12. Você possui sugestões para o aperfeiçoamento do quadro preparatório de docência dos alunos IBt? Comente* 